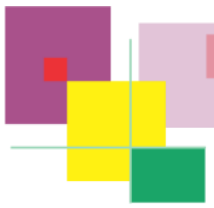

DOI: $10.20396 /$ lil.v24i48.8667918

\title{
Interculturalidade crítica rizomática e línguas de fronteira no Mato Grosso do Sul - Brasil
}

Critical rhyzomatic interculturality and border languages in Mato Grosso do Sul - Brazil \section{UFGD

\author{
Denise Silva** \\ IPEDI/UFGD
}

Gicelma da Fonseca Chacarosqui Torchi*

Daniel Valério Martins***

UFGD

\author{
Maiza Antonio**** \\ IPEDI/UFGD
}

Resumo: Este paper pretende discorrer sobre as linguas de fronteira no Mato Grosso do Sul. Esse trabalho nasce de algumas angústias sobre a maneira de como as línguas se relacionam dentro dos aspectos inerentes à educação, que deveria ser intercultural, fortalecendo a formação integral de crianças e jovens que residem nas regiões de fronteira. Sabemos que são as línguas que mobilizam, agregam $e$ desagregam, e inclusive integram ou não a comunidade escolar de modo que a escola se perceba como um importante espaço intercultural. Sendo assim, este artigo objetiva, prioritariamente, discorrer sobre o que vem a ser interculturalidade, como percebemos os processos interculturais, como entendemos a interculturalidade, especificamente interculturalidade crítica rizomática e como o papel 
desse conceito empara espaços interculturais no ensino das línguas nas fronteiras do Brasil, especificamente na fronteira sul de Mato Grosso do Sul/ Brasil.

Palavras-chave: Fronteira, Interculturalidade crítica rizomática, Linguas de fronteira.

Abstract: The objective of this paper is to discuss the border languages of Mato Grosso do Sul. This work arose from several concerns about the manner in which languages are related to inherent aspects of education, which should be intercultural, strengthening the basic education of children and young people who reside in border regions. We know it is the languages that mobilize, bring together and break apart, and even integrate or not the school community, in a way that the school perceives itself as an important intercultural space. Therefore, this article has the objective, primarily, to discuss what interculturality has come to be, how we perceive intercultural processes, how we understand interculturality, specifically critical rhizomatic interculturality, and how the role of this concept sustains intercultural spaces in the teaching of languages on the frontier of Brazil, specifically, on the southern border of Mato Grosso do Sull Brazil.

Keywords: Border, Critical rhizomatic interculturality, Border languages.

\section{Conceitos de Interculturalidade}

A interculturalidade é um conceito recém-desenvolvido, apesar disso não foram poucos os investigadores da comunicação, da antropologia, da sociologia e do marketing que já se debruçaram no mesmo. A noção distingue-se do multiculturalismo e do pluralismo pela sua intenção direta de fomentar o diálogo e a relação entre culturas. A interculturalidade tem lugar quando duas ou mais culturas entram em interação de uma forma horizontal e sinérgica. Assim, Valério (2016), parafraseando Alvarado (2003), estabelece uma distinção bastante clara entre os dois conceitos utilizando-os como etapas de um único 
processo denominado Sobreculturalidade ${ }^{1}$, afirmando que o multiculturalismo propõe a coexistência de culturas diferentes, em um mesmo espaço social, sob o princípio da tolerância e do respeito à diferença, e que a interculturalidade pressupõe uma inevitável interação entre as culturas desse mesmo espaço, estabelecendo um projeto político com base no diálogo entre elas, para garantir sua convivência pacífica.

Segundo Dávila (2012), o processo de interculturalidade surge quando o multicultural dialoga. Nessa mesma linha Valério (2016), explica a importância de observar essa passagem "MULTI -INTER", como etapas de um único processo transformador, que vê no diálogo o elo ou ponto de congruência. O processo intercultural, portanto, busca atenuar os conflitos, abismos e fronteiras culturais, unificando conhecimentos científicos, empíricos, tradicionais e filosóficos. Segundo Valério (2020), nesse aspecto, entramos na questão indígena, pois os povos indígenas e seus conhecimentos tradicionais são o que temos mais próximo do conhecimento unificado, que de uma maneira geral foi sendo fragmentado nas chamadas especialidades ao longo da história, enquanto o indígena ainda mantém seu conhecimento com base no contato com a natureza, experimentação, cosmovisão e filosofia.

Para tal, nenhum dos grupos culturais em contato se deve encontrar acima de qualquer outro que seja, favorecendo assim a integração e a convivência das pessoas. Este tipo de relações interculturais implica ter respeito pela diversidade; embora, por razões óbvias, o aparecimento de conflitos seja inevitável e imprevisível, podem ser resolvidos através do respeito, do diálogo e da concertação/assertividade. Segundo Luiz Lopes e E. W. Kupe (1999), a Interculturalidade é uma proposta filosófica, epistemológica, política e pedagógica que surge nos anos 70 do século XX, tanto na Europa como na América Latina possuindo perspectivas completamente diferentes. A primeira como resposta aos processos migratórios da periferia europeia e África. A segunda como consequência de um renascimento dos povos originários através de mobilizações indígenas e do desenvolvimento do chamado "neoindigenismo na intelectualidade pós-moderna" (TORRES, VELA, p. 25 /Tradução livre dos autores). 
De esta manera, se asume que la interculturalidad es algo que siempre ha existido en América Latina porque siempre ha existido el contacto y la relación entre los pueblos indígenas y afrodescendientes, por ejemplo, y la sociedad blanco-mestiza criolla, evidencia de lo cual se puede observar en el mismo mestizaje, los sincretismos y las transculturaciones que forman parte central de la historia y "naturaleza" latinoamericanacaribeña. (WALSH, 2009, p. 12).

Da dualidade de origem se desenvolvem, duas concepções ou atitudes sobre a interculturalidade, a Interculturalidade Funcional e a Interculturalidade Crítica, segundo Catherine Walsh, integrante do grupo Modernidade/Colonialidade. A Primeira concepção denominada como Interculturalidade Funcional própria da mensagem europeia, que está orientada à integração dos imigrantes africanos, árabes, índios e asiáticos na sociedade europeia que os acolhem como mãos de obra indispensável para seus processos de crescimento econômico. O objetivo da "inclusão social", e/ou assimilação, destas minorias nas sociedades modernas europeias e norte americana, como foco na diversidade cultural, que apesar de tratar da questão da inclusão social dentro da dinâmica dos Estados nacionais, não prima ou contempla o questionamento dos padrões de poderes institucionais e estruturais responsáveis pela desigualdade, pela exploração, pela dominação.

O conceito denominado de Interculturalidade Crítica tem como ponto de partida ou foco, especificamente a problemática do poder, buscando combater diretamente as questões de desigualdade, exploração e dominação, questionando também, o padrão de racialização e todas as injustiças decorrentes dessa postura. Por sua vez a Interculturalidade Crítica aparece como um fenômeno de resistência, de luta direta contra o racismo e a opressão, desta forma a interculturalidade crítica é por definição, anticolonialista, alcança âmbitos de direitos territoriais, políticos e culturais entre os quais "nos primeiros lugares está a educação cultural bilingue (EIB) que rechaça a educação homogeneizadora colonial" (TORRES, VELA, p. 25 /Tradução livre dos autores). Ou seja, 
la interculturalidad funcional asume la diversidad cultural como eje central, apuntalando su reconocimiento e inclusión dentro de la sociedad y el Estado nacionales (uni-nacionales por práctica y concepción) y dejando fuera los dispositivos y patrones de poder institucionalestructural -las que mantienen la desigualdad-, la interculturalidad crítica parte del problema del poder, su patrón de racialización y la diferencia que ha sido construida en función de ello. El interculturalismo funcional responde a y parte de los intereses y necesidades de las instituciones sociales dominantes; la interculturalidad crítica, en cambio, es una construcción de y desde la gente que ha sufrido un histórico sometimiento $\mathrm{y}$ subalternización. (WALSH, 2009, p. 12).

No Brasil, particularmente nas fronteiras brasileiras (em especial na fronteira Brasil/Paraguai) existe um cenário social multicultural, as crianças paraguaias, em sua maioria bilingues (falantes do espanhol e guarani) atravessam as linhas de fronteira para cursar o ensino fundamental e o ensino médio nas escolas brasileiras (a fronteira de Ponta Porã e Pedro Juan, por exemplo é apenas uma rua, o mesmo acontece com Coronel Bado e Coronel Sapucaia), essa população estudantil possui documentação brasileira, nascem em hospitais brasileiros e tiram identidade brasileira, assim como possuem documentação paraguaia). No entanto, apesar de receber essa população, a educação em escolas brasileiras é predominantemente monocultural, mantendo a ideia de divisão em guetos dentro de um mesmo espaço geográfico e de um contexto multicultural.

Os esforços da última década para atender uma escola que professasse uma educação intercultural bilíngue para os povos da fronteira foram restritos ao Programa Escolas Interculturais de Fronteira - $\mathrm{PEIF}^{2}$, que por sinal deixa oficialmente de funcionar, por falta de verbas do Governo Federal em 2015.

Desta forma, a educação fundamental e a educação de ensino médio (recentemente reformulada) segue com quase $80 \%$ de crianças e jovens paraguaios, (matriculados como brasileiros em escolas de fronteira), com ensino de língua e em língua (no caso a língua portuguesa apenas) 
insuficiente para a realidade da fronteira. Desta forma, vertendo um olhar para essa realidade, e pensando os conceitos de interculturalidade, em suas duas acepções (funcional e crítica) acreditamos que seria interessante observar a interculturalidade fronteiriça como uma Interculturalidade Crítica Rizomática, pois o rizoma representa no nosso entendimento os processos intrínsecos no âmbito das questões identitárias e dos direitos políticos e culturais que emergem (muitas vezes de forma insurgente) nas zonas de fronteira e que gritam por uma atenção especial.

Desta forma a Interculturalidade Crítica Rizomática teria sua episteme derivada de Rizoma, que trata-se de um modelo descritivo ou epistemológico na teoria filosófica de Gilles Deleuze e Félix Guattari (1995). A noção de rizoma foi adotada da estrutura de algumas plantas cujos brotos podem ramificar-se em qualquer ponto, assim como engrossar e transformar-se em um bulbo ou tubérculo; o rizoma da botânica, que tanto pode funcionar como raiz, talo ou ramo, independentemente de sua localização na figura da planta, servindo para exemplificar um sistema epistemológico onde não há raízes - ou seja, proposições ou afirmações mais fundamentais do que outras - que se ramifiquem segundo dicotomias estritas.

Um rizoma não começa nem conclui, ele se encontra sempre no meio, entre as coisas, inter-ser, intermezzo. A árvore é filiação, mas o rizoma é aliança, unicamente aliança. A árvore impõe o verbo "ser", mas o rizoma tem como tecido a conjunção "e... e... e..." Há nesta conjunção força suficiente para sacudir e desenraizar o verbo ser (DELEUZE; GUATTARI, 1995, p. 35).

O rizoma não se deixa conduzir ao Uno (n), ele foge da unidade, por isso podemos defini-lo como contra um fechamento, contrarregras préestabelecidas, o pensamento rizomático é movente e se abre, germina em todas as direções. Deleuze e Guattari (1995) propõem para a leitura de Mil Platôs a mesma estratégia de pensamento que pretendem apresentar e desenvolver ao longo da obra para a leitura do mundo: a abordagem rizomática que rompe com a linearidade aparente. Os sustentam o que, na tradição anglo-saxã da filosofia da ciência, costumou-se chamar de antifundacionalismo (ou antifundamentalismo, 
ou, ainda, antifundacionismo): a estrutura do conhecimento não deriva, por meios lógicos, de um conjunto de princípios primeiros, mas sim elabora-se simultaneamente, a partir de todos os pontos sob a influência de diferentes observações e conceitualizações. Isto não implica que uma estrutura rizomática seja necessariamente flexível ou instável, porém exige que qualquer modelo de ordem possa ser modificado: existem, no rizoma, linhas de solidez e organização fixadas por grupos ou conjuntos de conceitos afins. Tais conjuntos definem territórios relativamente estáveis dentro do rizoma.

Seguindo essa mesma analogia às partes de uma árvore, assim como fazem algumas comunidades indígenas entre seus membros, Valério (2020) mostra que nesse processo está intrínseca a ideia de aculturação de Egon Schaden (1969) como raízes do processo de contato, nos remetendo a uma "antropologia do vovô" como define o autor explicado em Welter e Martins (2013), que por sua vez ganha robustez no surgimento do pensamento da intraculturalidade de Aparício e Delgado (2014) como tronco, chegando na divisão proposta por Ribeiro(1962), que gerou frutos, como exemplo, o próprio Estatuto do Índio, chegando nas sementes como propagação e sobrevivência da espécie, (no caso da árvore), que seria o processo de Sobreculturalidade de Valério (2016), multiplicado e propagado com a educação diferenciada e intercultural.

\section{A fronteira}

A fronteira se diferencia por ser um espaço heterogêneo, intrincado e mestiço, é o espaço das diferenças, do entrelugar, onde tudo se mistura e se mescla. O Brasil apresenta cerca de $23.086 \mathrm{~km}$ de fronteira ${ }^{3}$ sendo que $7.367 \mathrm{~km}$ são marítimas e $15.719 \mathrm{~km}$ fazem fronteira com quase todos os países localizados no continente sul-americano. Ficam de fora apenas o Chile e o Equador. A faixa de fronteira interna do país, ao longo dos seus $15.719 \mathrm{~km}$, corresponde a $150 \mathrm{~km}$ de largura, abrangendo 588 municípios. Desse total, 72 municípios estão localizados na faixa de fronteira de Mato Grosso do Sul, onde 03 cidades são linha de fronteira (Amambaí, Aral Moreira e Coronel Sapucaia) e 05 são cidades-gêmeas (Bela Vista, Corumbá, Mundo Novo, Paranhos e Ponta Porã). O estado faz fronteira com outros dois países sul-americanos: Paraguai e Bolívia. Na faixa de fronteira 
encontram-se 13.640 escolas de educação básica que ofertam educação infantil, ensino fundamental e ensino médio, incluindo instituições públicas e privadas com um número total de 2.627.797 estudantes matriculados, conforme o Censo Escolar de 2013.

Estes dados nos fazem pensar nas escolas localizadas nessa faixa de fronteira e refletir se essa mistura de línguas e culturas pode se tornar a primeira barreira de acesso e permanência na escola levando esses alunos ao fracasso escolar. Este breve panorama situacional e geográfico brasileiro se faz necessário para que possamos entender este cenário fronteiriço que apresenta características bem próprias e que fogem da realidade das demais regiões do país. Uma região que necessita de uma política linguística forte, de valorização da diversidade cultural, que promova a integração da região e que garanta uma educação intercultural e com qualidade.

Para Caterine whalch (2012), a interculturalidade latino-americana se vislumbra como uma interculturalidade positivamente crítica que se afirma como uma visão decolonizadora entre a cultura hegemônica eurocêntrica e as culturas tidas como subalternas". É uma interculturalidade que fomenta pedagogias críticas que promovem afirmações dos saberes latino-americanos e que segundo Edgar Lander (2005) foram sequestrados por culturas hegemônicas. Precisamos melhorar a qualidade de ensino através da renovação do enfoque didático tradicional, cuja finalidade não tem sido outra senão fortalecer o modelo "monocultural" ou "multicultural de guetos" e colonial de nossa sociedade brasileira e de todas as sociedades (umas menos, outras mais) latino-americanas.

O Brasil é um país multicultural e mestiço por excelência e as fronteiras brasileiras potencializam essa premissa. Por mestiçagem entendemos a mistura de culturas, não apenas de povos que circulam na Fronteira. Não trabalhamos com o conceito de Povos-Novos, no entanto deixaremos registrado que, em As Américas e a Civilização (1970), o antropólogo Darcy Ribeiro (1922-1997) definira Povos-Novos como povos que se constituíram "pela confluência de contingentes profundamente díspares em suas características culturais e linguísticas, como um subproduto de projetos coloniais europeus" (RIBEIRO, 1983, p. 92). Dessa forma, para o autor, a feição básica destes povos é mestiça, tanto em seus aspectos raciais quanto culturais. Ribeiro advoga ainda que, no encontro de povos surgiram: 
(...) línguas francas como instrumentos indispensáveis de comunicação e se edificaram em culturas sincréticas feitas de pedaços tomados dos diferentes patrimônios que melhor se ajustavam a suas condições de vida (RIBEIRO,1983, p. 92).

Estes Povos-Novos, no entanto, não são nacionalidades multiétnicas, "visto que, em todos os casos, houve um processo de formação violenta o suficiente para compelir a fusão das matrizes originais em novas unidades homogêneas" (RIBEIRO, 1983, p. 93). Na violência desse processo, a escravidão aparece como elemento decisivo, pois, operando de forma destribalizadora, desgarrava as "novas criaturas" das tradições ancestrais para transformá-las no subproletariado da sociedade nascente:

Nesse sentido, os Povos-Novos são produto, tanto da de culturação redutora de seus patrimônios tribais indígenas africanos, quanto da aculturação seletiva desses patrimônios e da sua própria criatividade face ao novo meio. (RIBEIRO, 1983, p. 94).

Segundo Schaden (1969), Darcy Ribeiro passa a formular recomendações práticas de ação protecionistas tais como: legalização da posse das terras, organização da economia tribal, estatuto jurídico do índio, assistência médica, educação, medidas específicas para indígenas de fronteiras, trabalho das missões religiosas e "aproveitamento dos conhecimentos antropológicos para uma atuação mais eficiente em todos os setores". E assim ganha força a tentativa de um processo assimétrico.

Nossa pesquisa amplia as apreciações de Darcy Ribeiro alocando considerações que por sua vez, na nossa visão, dão conta de ler a fronteira de forma híbrida, misturada, mestiça. Para Darcy Ribeiro, o conceito de Povos-Novos está intimamente ligado ao conceito de identidade étnica e atualização histórica. Para nós, no caso da fronteira, nos interessa o conceito de mestiçagem, pois acreditamos ser esse o que mais descreve as identidades fronteiriças que por sua vez delimitam o 
pertencimento, apontando exigências de atuação para os sonhos dos povos que vivem nas fronteiras.

Apesar de entendermos a fronteira como mestiça, sabemos que as relações entre as pessoas de diferentes culturas (mesmo culturas que se misturam) na semiosfera ${ }^{4}$ da fronteira que deveria ser de respeito intercultural e de igualdade, ainda reflete, lamentavelmente, a subordinação colonial. Essa situação de colonialismo se expressa através do preconceito, principalmente do preconceito linguístico presente nas relações interpessoais e inclusive nas determinações curriculares, pois a Lei de Diretrizes e Bases da Educação Nacional dita que o inglês seja prioridade no ensino da língua estrangeira e o estado do Mato Grosso do Sul segue essa premissa.

\section{Um Lugar Chamado "Fronteira": espaços interculturais}

O espaço da fronteira é diverso cultural e linguisticamente, e a convivência de várias culturas no espaço da fronteira e das escolas de fronteiras tem sido uma constante. A fronteira se caracteriza por ser uma zona heterogênea, peculiar, ímpar e única (PEREIRA, 2014), onde podemos encontrar duas ou mais línguas convivendo em um mesmo espaço. De acordo com Sturza:

(...) a fronteira assume sentidos contraditórios, que se definem não só pelos limites geográficos como também pelo conteúdo social. (...) na base de todo conceito de fronteira, está a sua natureza constituída, antes de tudo, pela latência de contato - contato de territórios, contato de pessoas, contato de línguas. (2006, p.19).

Silva também traz uma concepção de fronteira dizendo que:

Uma fronteira representa muito mais do que uma mera divisão e unificação dos pontos diversos. Vai além do limite geográfico. É um campo de diversidades. É o encontro com o "diferente" físico e social. E é nesse espaço que as relações se formam e se deformam. Completam-se e dão forma à diversidade, à cultura. Por meio de amizades e companheirismo formam-se famílias, amigos e irmãos. (2011, p. 63). 
Para Bhabha (1998, p. 19), "uma fronteira não é o ponto onde algo termina, mas, como os gregos reconheceram, a fronteira é o ponto a partir do qual algo começa a se fazer presente". Lótman (1996) apresenta a fronteira como uma zona irregular, complexa e mestiça, um espaço de trânsito e fluidez. É o espaço das diferenças, do entrelugar, onde tudo se mistura e se mescla. Para Lótman, ainda, a fronteira é como uma semiosfera, um espaço importante e necessário para que a linguagem e a cultura possam existir, evoluir e funcionar. Neste sentido Machado completa dizendo que:

Nesse espaço, natureza e cultura vivem uma
relação de complementariedade, alterando
completamente o conceito de fronteira. Em vez de
linha demarcatória e divisória, fronteira designa
aquele segmento de espaço onde os limites se
confundem, adquirindo a função de filtro. (2003,
p. 163-164).

Como podemos perceber não há como pensar na fronteira apenas como uma linha ou faixa demarcatória que indica onde um país com sua língua, cultura e tradições termina e outro começa. Fronteira é muito mais que isso é o entrelaçar de línguas e culturas, mesclando o que está posto, transformando em mestiço algo que "aparentemente" era puro ao mesmo tempo em que preserva os traços de cada língua e de cada cultura. O conceito de Fronteira está ligado ao espaço da semiosfera,
(...) o espaço semiótico necessário para a existência e funcionamento da linguagem e da cultura com sua diversidade de códigos. (...) A semiosfera diz respeito à diversidade, condição para o desenvolvimento da cultura (MACHADO, 2003, p. 164).

Semiosfera é onde as semioses entre línguas e culturas coexistem e coevoluem filtrando e adaptando essas relações. $\mathrm{Na}$ visão de Chacarosqui-Torchi semiosfera, 
(...) é um espaço semiótico, dentro do qual se realizam os processos comunicativos e a produção de novas informações. É impossível haver semiose fora da semiosfera. $O$ conceito de semiosfera corresponde portanto, a conexão de sistemas e geração de novos textos. Trata-se de um espaço que possibilita a realização dos processos comunicativos e a produção de novas informações, funcionando como um conjunto de diferentes textos e linguagens (CHACAROSQUITORCHI, 2008, p. 7).

Diante deste cenário único, mestiço, intercultural é que tomamos como base teórica para esta pesquisa o pensamento Intercultural de semiótica da cultura por acreditar que é a teoria que melhor explica essas relações fronteiriças onde ela procura "entender a comunicação como sistema semiótico e a cultura como um conjunto unificado de sistemas, ou melhor, como um grande texto" (MACHADO, 2003, p. $164-165)$.

Os estudos voltados para a cultura quanto sistemas de signos nasceram dentro do Departamento da Universidade de Tártu, Estônia nos anos 60 dando origem à Escola Tártu-Moscou, tendo como grande nome Yuri Lótman. A semiótica da cultura surgiu da necessidade em tentar compreender os problemas da linguagem "não como uma teoria geral dos signos e das significações, mas como uma teoria de caráter aplicado voltada para o estudo das mediações ocorridas entre fenômenos diversificados" (MACHADO, 2003, p. 25). Um exemplo disso seria estudar o cinema enquanto linguagem. Desta forma a Escola de Tartu-Moscou se constituiu como um espaço de discussões entre pesquisadores que procuravam compreender o papel da cultura na linguagem, ou seja, a linguagem nas suas várias manifestações culturais.

Na concepção da Escola de Tartu-Moscou, "cultura é um conjunto de informações não hereditárias que são armazenadas e transmitidas por grupos em domínios diferenciados de manifestação da vida" (MACHADO, 2003, p. 157). É constituída de um conjunto de informações que cada grupo social acumula durante sua convivência com o meio e no processo de filtrar e adaptar transmite a outros através das manifestações culturais. 
No cenário de nossas fronteiras brasileiras vemos claramente as línguas portuguesa, espanhola e o guarani convivendo dentro da semiosfera fronteiriça, cada qual com suas culturas, costumes, crenças e nenhuma é anulada pela outra, nenhuma prevalece sobre a outra, pelo contrário, aprendem a conviver, filtrando e adaptando suas formas. Segundo Machado, "as culturas não se anulam, mas propiciam outras injunções" (2003, p. 32) e para Bakhtin "a cultura alheia só se revela em sua completude e em sua profundidade aos olhos da outra cultura (e não se entrega em sua plenitude, pois virão outras culturas que verão e compreenderão ainda mais)" (1997, p. 368).

Nesse sentido, assim como afirma Valério (2018), para lograr a sobreculturalidade como sobrevivência cultural, precisa-se passar por uma intraculturalidade, quando pressupõe a autoaceitação e o autorreconhecimento para atingir um desenvolvimento interno pessoal ou comunitário, pois busca, sobretudo, uma autorrealização do sujeito, e o meio de se alcançá-la, nada mais é que o reconhecimento e interação com o outro, com base no diálogo, respeito e na aceitação das diferenças, negando-se preconceitos muitas vezes camuflados.

As culturas presentes na semiosfera fronteiriça dialogam uma com a outra e esse diálogo acontece a partir do que cada uma tem de diferente e comum em relação a outra, ou seja, "quando dois indivíduos (ou sistemas) se encontram, compartilham experiências por meio de um processo de experimentação do outro: um 'enxerga' o outro a partir da própria experiência, da própria noção que tem de si” (VELHO, 2009, p. 253). Desta forma Bakhtin afirma que,

Um sentido revela-se em sua profundidade ao encontrar e tocar outro sentido alheio; estabelecese entre eles como um diálogo que supera o caráter fechado e unívoco. Formulamos a uma cultura alheia novas perguntas que ela mesma não se formulava. Buscamos nela uma resposta a perguntas nossas, e a cultura alheia nos responde, revelando-se nos seus aspectos novos, suas profundidades novas de sentido. (...) $\mathrm{O}$ encontro dialógico de duas culturas não lhes acarreta a fusão, a confusão; cada uma delas conserva sua própria unidade e sua totalidade aberta, mas se 
enriquecem mutuamente (BAKHTIN, 1997, p. $368)$.

\section{Metodologia}

Para a realização deste paper, optamos por utilizar a pesquisa qualitativa, por se tratar de uma pesquisa que busca nos documentos (documentos oficiais, decretos, leis, portarias e tratados, etc,), além de teóricos que versaram sobre as categorias abordadas, os dados necessários para discutir os processos de empoderamento e subjugação de algumas línguas de fronteira, tentar descrevê-los e/ou explica-los e ainda refletir sobre eles. A razão pela escolha por esse tipo de pesquisa se dá porque ela oferece três modalidades: a documental, o estudo de caso e a etnografia. Sendo assim nossa pesquisa buscará as informações necessárias através da pesquisa documental.

Segundo Gresller (2003), nas pesquisas qualitativas é frequente que o pesquisador procure entender os fenômenos situando sua interpretação.

Quanto às qualidades essenciais da pesquisa, Bogdan e Biklen (apud. LUKLE e ANDRÉ, 2013) apresentam cinco características da pesquisa qualitativa que foram estabelecidas pelos autores em seu livro intitulado: A Pesquisa Qualitativa em Educação. De acordo com Bogdan e Biklen, essas características estão fundadas nas seguintes questões: ter um ambiente natural como fonte de pesquisa e de dados tendo como principal instrumento o pesquisador; a coleta de dados é preferencialmente descritiva, seja de pessoas, acontecimentos ou situações; ter uma preocupação com o produto e não com o processo em si; o pesquisador deve ter a sua atenção focada ao significado que é dado as coisas pelas pessoas que estão envolvidas no processo; a análise dos dados quase sempre segue o processo indutivo (2013, p. 12-14).

Segundo Ludke e André, a análise documental "pode se constituir numa técnica valiosa de abordagem de dados qualitativos, seja complementando as informações obtidas por outras técnicas, seja desvelando aspectos novos de um tema ou problemas" (2013, p. 45). Esses autores ainda dizem que "os documentos constituem também uma fonte poderosa de onde podem ser retiradas evidências que fundamentem afirmações e declarações do pesquisador" (p. 45). Assim, a pesquisa documental se caracteriza por permitir que o pesquisador 
examine materiais que já foram ou não examinados em busca de uma interpretação importante e/ou uma interpretação nova ou ainda que venha ser complementar àquela já feita anteriormente.

Por fim, destacamos alguns passos metodológicos que julgamos ser importantes na consolidação deste trabalho. A primeira etapa da pesquisa se deteve no levantamento de toda produção bibliográfica e documental sobre o tema proposto. Em seguida foi feita uma discussão sobre os dados levantados, delimitando o campo de nossa pesquisa, com bases na teoria da semiótica da cultura e discutindo conceitos de fronteira, cultura, interculturalidade, sobreculturalidade, língua, mestiçagem e semiosfera.

\section{Considerações Finais}

É no cenário complexo das fronteiras que encontramos milhares de crianças e adolescentes convivendo, dentro das escolas, com essa diversidade de línguas e culturas. Diante disso faz-se necessário pensar num currículo escolar que contemple essa realidade possibilitando a integração de todos os processos educativos da escola de forma a construir um projeto político-pedagógico que tenha como ponto de partida a interculturalidade.

Percebe-se que é muito importante respeitar as diferenças linguísticas que esses alunos trazem para o ambiente escolar, promovendo uma convivência democrática entre as diferentes culturas que estão circulando na escola, integrando-as de forma a não anular sua diversidade por meio do enriquecimento mútuo proposto em modelos interculturais. Para os semioticistas russos, cultura é entendida como linguagem e essa linguagem é "o elo que une domínios diferentes da vida no planeta" (MACHADO, 2003, p. 25).

Desta forma, a língua não se separa da cultura, uma não existe sem a outra, na verdade uma está dentro da outra de maneira complementar, ou seja, "O homem se apropria do mundo estudando a língua, decifrando o texto relativo e traduzindo-o em uma língua que lhe é acessível. Língua e cultura são indivisíveis" (MACHADO, 2003, p. 157-158).

Negar essa complementaridade de conceitos e culturas em contato, é dispensar a possibilidade de enriquecermos em somas de culturas entre os diferentes, é tentar limitar a identidade do indivíduo a um único 
espaço geográfico, desrespeitando o direito de ir e vir, de escolha de uma nacionalidade, e de liberdades individuais e coletivas como bem pregam os Direitos Humanos e Fundamentais quanto à dignidade humana.

\section{Referências}

ALVARADO, Neritza. La atención de la pobreza em Venezuela: del gran viraje a la Quinta República 1999-2002. Caracas: Ediciones de la Fundación Escuela de Gerencia Social, 2003.

APARÍCIO, J. M. \& DELGADO, M. A. La Educación Intercultural en la Formación Universitaria Europea y Latinoamericana. Segovia: ITAMUT- FIFIED, 2014.

D'ÁVILA, A. M. Da coexistência à convivência com o outro: Entre o multiculturalismo e a interculturalidade.Rev. Inter. Mob. Hum.ano XX, no 38, p. 67-81, jan./jun. 2012.

RIBEIRO, D. A política Indigenista Brasileira. Rio de Janeiro: Ministério da Agricultura, 1962.

SCHADEN, E. Aculturação Indígena. São Paulo: Editora da USP, 1969.

VALÉRIO, D. M., \& KNAPP, C. Proposta de uma metodologia intercultural na construção de artigos científicos por estudantes indígenas do PPGET $\neg$ UFGD. Cadernos CERU, 31(2), 137-148, 2020.

VALÉRIO, M. D., Gortari, A.L. \& Bravo, M.P. Conceitos de Contatos Culturais e de Intervenção Social que Incidem na Sociedade Latinoamericana do Século XXI: Intra, Multi, Inter, Trans e Sobreculturalidade. Revista Pluri - Vol. 1, No 1, 2018.

VALÉRIO, M. Daniel. A intraculturalidade nas comunidades indigenas da Região Metropolitana de Fortaleza - Ce - Brasil: Caminho para o desenvolvimento e sobreculturalidade. Salamanca: Ediciones Vitor, 2016.

WELTER, T. \& MARTINS, P. Atualidade da Obra de Egon Schaden no centenário de seu nascimento. São Paulo: Plural Revista de Ciências Sociais, v.20 n.2, 2013.

Notas 
* Graduada em Letras pela UFMS e Pós-Doutorado pela Universidade Federal do Mato Grosso, UFMT, Programa de Pós-Graduação em Estudos de Culturas Contemporâneas PPGECCO/UFMT. Atualmente, é professora Adjunta na Universidade Federal da Grande Dourados, UFGD, Faculdade de Comunicação Artes e Letras (FACALE) e do Programa de Pós-Graduação em Letras da UFGD, área de Linguística e Transculturalidade.

** Licenciada em Pedagogia pela Universidade Federal de Mato Grosso do Sul (UFMS) e Pós-doutorado em Linguística e Língua Portuguesa pela Universidade Estadual Paulista Júlio de Mesquita Filho (Unesp). Atualmente, é Professora Visitante do Programa de Pós- Graduação em Letras da FACALE/UFGD.

*** Graduado em Pedagogia pela Universidade Estadual do Vale do Acaraú e Doutor em Antropologia, Instituto de Ibero-América - USAL. Atualmente, é professor do Programa de Pós-Graduação em Educação e Territorialidade - PPGET da UFGD.

**** Licenciada em Linguagens na Licenciatura Intercultural Indígena Povos do Pantanal, atualmente é aluna especial do Programa de Pos-graduação em Letras da FACALE- UFGD.

1 Para Valério (2016) esses dois conceitos são etapas de um todo mais amplo denominado Processo de Sobreculturalidade. Estas etapas já debatidas e trabalhadas por vários teóricos (pedagogos e antropólogos) são as seguintes: (intra - multi - inter e transculturalidade), fases do "conhecer-se e aceitar-se", "conhecer e respeitar o outro" e "interagir" na busca de um desenvolvimento pessoal e comunitário, a fim de gerar uma transformação ou uma "transcultura" (nas formas de pensar e atuar consigo e com os demais), para, em seguida, lograr a "sobrevivência" como um ser humano e cultural, passível de direitos e deveres. Para que ocorra esse processo denominado Sobreculturalidade, pressupõe-se a existência de culturas que foram submetidas a todas as etapas anteriormente citadas, com o propósito de sobreviver e propagar sua cultura, perpetuando-a. esse processo, ademais de obter como produto final a convivência intercultural, visa, por meio desta, alcançar a promoção do respeito e tolerância ao diferente, e ao mesmo tempo ponderar entre a perda ou soma de culturas com o contato, iniciado pela "intraculturalidade" rumo à "sobreculturalidade".

${ }^{2}$ O Programa Escolas Interculturais de Fronteira (PEIF) se trata de uma ação do Ministério da Educação (MEC) em parceria com universidades, escolas e secretarias de educação localizadas nas fronteiras do Brasil com escolas e instituições educativas dos países vizinhos.

3 Dados do IBGE, fonte http://teen.ibge.gov.br/mao-na-roda/posicao-e-extensao acessado em 03/07/2014.

${ }^{4} \mathrm{O}$ Universo semiótico é como um conjunto de distintos textos e linguagens, unidos uns com os outros, como um edifício construído com diversos ladrilhos. Estes diversos ladrilhos semióticos, formam o grande edifício da semiosfera, não esquecendo que o conceito de semiosfera está ligado a determinada homogeneidade e individualidade semióticas (LOTMAN, 1996, p. 12). Posto que todos os níveis da semiosfera, desde a pessoa do homem, até um texto, são unidades semióticas globais. Elas representam assim, semiosferas colocadas umas dentro das outras, onde cada uma manifesta a propriedade de ser direita ou esquerda no espaço do diálogo (LOTMAN, 1996, p. 25). Ou seja, cada semiosfera tem visão, compreensão e interpretação própria. Portanto, 
quando duas semiosferas se encontram, surge um dos conceitos fundamentais do caráter semioticamente delimitado: a fronteira. (LOTMAN, 1996, p. 12). Tradução livre dos autores. 